\title{
Neuregulin-1, in a Conducive Milieu with Wnt/BMP/Retinoic Acid, Prolongs the Epicardial-Mediated Cardiac Regeneration Capacity of Neonatal Heart Explants
}

\author{
Arora $\mathrm{H}^{1,2 \#}$, Lavin $\mathrm{AC}^{1 \#}$, Balkan $\mathrm{W}^{1,3}$, Hare $\mathrm{JM}^{1,3}$, White $\mathrm{IA}^{1,4}$
}

\begin{abstract}
Rationale: Cardiac sympathetic nerves are required for endogenous repair of the mammalian neonatal heart in vivo, but the underlying mechanism is unclear.

Objective: We tested the hypothesis that a combination of cardiac developmental growth factors Wnt3a, BMP4 and Neuregulin (NRG-1), compensate for denervation and support cardiac regeneration in explanted neonatal mammalian hearts.

Methods and Results: Hearts from 2-day old neonatal mice were harvested, lesioned at the apex and grown ex vivo for 21 days under defined conditions. Hearts grown in canonical cardiomyocyte culture media underwent complete coagulative necrosis, a process resembling ischemic cell death, by day 14. However, the addition of Wnt3a, BMP-4 and NRG-1, maintained cellular integrity and restored the endogenous regenerative program. None of these factors alone, or in any paired combination, were sufficient to induce regeneration in culture. rNRG-1 alone significantly reduced the accumulation of double strand DNA damage at Day 3; (-NRG- $1: 60 \pm 12 \%$; + NRG-1: $8 \pm 3 \%$; $\mathrm{P}<0.01$ ) and prevented coagulative necrosis at Day 14. Short-term addition of rWnt3a and rBMP-4 (day 0-3, NRG-1+) increased WT1 expression (a marker of epicardial cells) 7 -fold, epicardial proliferation ( $78 \pm 17$ cells vs. $21 \pm 9$ cells; $\mathrm{P}<0.05$ ), migration and recellularization $(80 \pm 22$ vs. zero cells; $\mathrm{P}<0.01 ; \mathrm{n}=6)$ at the injury site on day 14 .

Conclusions: A novel explant culture system maintains three-dimensional neonatal mouse hearts and the mammalian neonatal cardiac regenerative program ex vivo. We identified that rNRG-1, plus short-term activation of Wnt- and BMP-signaling, promotes cardiac repair via epicardial cell activation, their proliferation and migration to the injury site, followed by putative cardiomyocyte recruitment. This novel technique will facilitate future studies of mammalian cardiac regeneration and may be useful in cardiac-specific drug testing.
\end{abstract}

Keywords: Cardiac regeneration; Tissue regeneration; Epicardial stem cells; Drug model; Heart repair; Neonatal mouse; Cardiomyocytes; Nerves; Regenerative medicine

\section{Introduction}

Cardiovascular disease accounts for more deaths than any other disease $^{[1]}$, in large part due to an inability of the adult mammalian heart to sufficiently regenerate lost tissue following injury. Lower vertebrates, e.g., teleost fish species and urodele amphibians, such as the newt, retain a capacity to regenerate lost cardiac tissue through a process that involves activation of the epicardium and cardiomyocyte proliferation ${ }^{[2-5]}$. Until recently, it was thought that the mammalian heart was incapable of such a response to acute injury. However, recent discoveries challenge this view; neonatal mouse and pig hearts undergo complete repair following resection $^{[6]}$ and infarction ${ }^{[7,8]}$ of the left ventricle, respectively. Furthermore, $0.45-1 \%$ of human cardiomyocytes are replaced per year throughout life ${ }^{[9]}$. These findings have propelled a major drive toward determining the mechanisms of endogenous mammalian cardiac regeneration.

It is clear that the absence of cardiac autonomic nerves compromises repair of the neonatal mouse heart ${ }^{[10-12]}$. Ablation of either the sympathetic ${ }^{[12]}$ or parasympathetic ${ }^{[1]}$ cardiac nerves abrogates the innate regenerative potential of the neonatal heart, suggesting that non-redundant contributions from both branches of autonomic nerves are required to support full cardiac regeneration. Neuronal input may also be required for cardiac homeostasis, as heart failure following cardiac transplantation, where the transplanted heart is denervated, remains a common outcome $e^{[13]}$.

Following experimental parasympathectomy, local administration of Neuregulin (NRG-1), a cardiomyocyte growth factor, rescued regeneration following apical injury to murine neonatal hearts though a mechanism of cardiomyocyte proliferation ${ }^{[14]}$. In these in vivo experiments, sympathetic nerves are presumably intact, making it difficult to tease apart the relationship and relative contributions of each branch of the autonomic nervous system.

In the heart, NRG-1 is produced primarily by cardiac endothelial cells in response to $\beta$-adrenergic signals from sympathetic cardiac nerves. The tyrosine kinase receptors for NRG-1 (ErbB2 and ErbB4) are located on the surface of neighboring cardiomyocytes $^{[14]}$, where signals are transduced into the cell following receptor heterodimerization. During the first seven postnatal days, ErbB2 expression is progressively downregulated on the membrane surface of cardiomyocytes ${ }^{[15]}$, coinciding temporally with a loss in regenerative potential[ ${ }^{[6]}$.

To address the role of NRG-1 in the denervated heart, we developed a novel explant model of mammalian cardiac regeneration. With this technique, whole neonatal hearts can be maintained in culture under defined conditions. Explanted neonatal hearts are totally 
denervated and exhibit no regenerative activity. Here, we report that continuous administration of NRG-1 and RA plus brief exposure to Wnt3a and BMP-4 was sufficient to induce epicardial activation and homing of epicardial cells to the site of experimental injury, activated embryonic transcription factors, $\mathrm{Nkx2-5}$ and GATA416 and subsequent recellularization of the ventricular myocardium in explanted, injured neonatal hearts. Together, these data suggest that the regenerative contribution from cardiac nerves can be compensated for, and the neonatal regenerative window can be extended, with appropriate and timely exposure to $\mathrm{Wnt} / \beta$-catenin and BMP/RA signaling together with NRG-1 in mammalian cardiac explants.

\section{Methods}

\section{Culture Media}

Maintenance media $($ Base $+\mathrm{P}+\mathrm{N}$ ) consisted of DMEM/F12 (Invitrogen, cat. no. 15090), $2 \%$ probumin (Millipore, cat. no. 82-100-5), $50 \mathrm{U} / \mathrm{mL}$ Penicillin-streptomycin (Gibco, \#15140-148), 2 mM 1-Alanyl-1glutamine (Cellgro, cat. no. 25-015-CI), 1\% MEM non-essential amino acids (Cellgro, cat. no. 25-025-CI), $0.1 \mathrm{mM}$ 2-Mercaptoethanol (inVitrogen, 21985-Cl), $50 \mu \mathrm{g} / \mathrm{mL}(+)$-Sodium 1-ascorbate (Sigma, \#A4034), $10 \mu \mathrm{g} / \mathrm{mL}$ bovine transferrin (Invitrogen, \#11107-018), 8 $\mathrm{ng} / \mathrm{mL}$ rhFGF2 (Invitrogen, \#PHG0023), 10ng/mL rhActivin-A (R\&D, \#338-AC), 200ng/mL LONGR3 IGF-I human (Sigma, \#85580C) and 10ng/mL rhNRG-1 (R\&D, \#396-HB). Activation media (AM) consisted of maintenance media $($ Base $+\mathrm{P}+\mathrm{N})$ with the addition of 25 $\mu \mathrm{g} / \mathrm{L}$ rmWnt3a (R\&D \#1324-WNP), $100 \mu \mathrm{g} / \mathrm{L}$ rmBMP4 (R\&D \#5020$\mathrm{BP})$ and $4 \mu \mathrm{M}$ retinoic acid (Sigma, \#R2625). Regenerative media (Base $+\mathrm{NWB})$ consists of maintenance media $($ Base $+\mathrm{P}+\mathrm{N})$ with the addition of $4 \mu \mathrm{M}$ retinoic acid.

\section{Ex vivo Maintenance of Neonatal Mouse Heart}

Two-day-old mice were decapitated and partially exsanguinated by blotting with absorbent paper. Cadavers were submerged in cold PBS on a $10 \mathrm{~cm}$ petri dish and opened using needle nose tweezers (Roboz, Gaithersburg, MD, USA). Hearts were removed by pinching the outflow tract at the base of the heart and placed into a clean petri dish containing ice cold PBS (Cellgro, \#21-031). Hearts were exsanguinated by extensive massaging and palpating with the flat portion of the tweezers. During collection, hearts were temporarily stored in clean ice-cold PBS, prior to culture. Hearts were placed into $60 \mathrm{~mm}$ tissue culture plates (BD, \#35004) and maintained (4-5 per plate) in $4 \mathrm{~mL}$ maintenance media in a $37^{\circ} \mathrm{C}, 5 \% \mathrm{CO}_{2}$ humidified cell culture incubator. Every third day of culture, $80 \%$ of the media was gently aspirated and replaced with fresh, pre-warmed media.

\section{Induction of Endogenous Cardiac Regeneration}

To induce innate cardiac regeneration, hearts were mechanically injured and cultured in regeneration media for up to 21 days. Hearts were obtained and washed as described above. While submerged in ice cold PBS each heart was visualized with a stereo dissecting microscope and injured by cutting the apex (at left ventricular free wall) with the tip of a $30 \mathrm{G}$ hypodermic needle (BD, \#305106) through the application of downward force. Hearts were immediately placed in $4 \mathrm{~mL}$ activation media at a density of $4-5 / 60 \mathrm{~mm}$ plate and maintained at $37^{\circ} \mathrm{C}$ in a $5 \% \mathrm{CO}_{2}$ humidified cell culture incubator. After 72 hours, $80 \%$ of media was carefully aspirated and replaced with an equal volume of regeneration media (Base+NWB). Hearts were incubated for 72 hours. Again $80 \%$ of media was aspirated and replaced with regeneration media. Hearts were maintained in regeneration media up to day 21 , exchanging $80 \%$ of the media every 72 hours.

\section{Histologic Analysis}

Hearts were harvested at various time points for analysis by immunohistochemistry and immunofluorescence. The tissue was washed in PBS prior to fixation in 4\% PFA (Thermo Scientific Rockford, IL, \#28906) at room temperature for 15 minutes, prepared for cryo-embedding by placing into $30 \%$ sucrose solution until reaching equilibrium and subsequently embedded in clear frozen section compound (VWR, \#95057-838). Tissue sections were cut at a thickness of $10 \mu \mathrm{M}$ using a Leica CM1850 cryostat and mounted on positively charges microscope slides (Fisher, \#12-550-17), air dried and stored at negative $80^{\circ} \mathrm{C}$ prior to histology. Gross morphology was evaluated with hematoxylin and eosin (Sigma, \#HMS16, \#318906), immunohistochemistry rabbit anti-mouse Wt1 (abcam, \#ab96792), mouse anti- $\beta$-MyHC (DSHB, \#A4.951-c) and immunofluorescence rabbit Nkx2.5 (Pierce, \#PA5-21686) rabbit Is11 (millipore, \#AB4326), goat anti-mouse TBX18 (Santa Cruz, \#sc17869), rabbit anti-mouse GATA4 (Pierce, \#PA1-102), anti-BrdUFITC (Millipore, \#MAB3262F), DAPI (Life Technologies, \#R37606). Hearts were incubated with EdU (details of dosage and length of exposure are specified in Figure legends) and harvested as described. After being allowed to dry at room temperature, sections were stained using a Click-iT EdU Alexa Flour 594 Imaging Kit (Life Technologies, 1753456) and counterstained with DAPI (Life Technologies, R37606). Positive cells were imaged using an Olympus IX81 fluorescent microscope and quantified using NIH Image J software.

\section{RNA Preparation and Quantitative Real-Time PCR}

Total RNA was extracted from cells using the TRIzol method (Thermo Fisher Scientific, \#15596026), and then reverse transcribed to complementary DNA using High-Capacity cDNA Reverse Transcription Kits (Applied Biosystems, USA) according to the manufacturer's protocol. Quantitative RT-PCR for indicated genes was performed using TaqMan ${ }^{\mathrm{TM}}$ probes ERBB2, WT1, NKX2.5, GATA4, TBX5, and c-KIT and TaqMan ${ }^{\mathrm{TM}}$ Universal PCR Master Mix (Applied Biosystems, USA) and TaqMan ${ }^{\mathrm{TM}}$ Gene Expression Assays according to manufacturer's protocol. Samples were analyzed using the BIORAD sequence detection system (Bio-Rad, Hercules, CA, USA). All PCR reactions were performed in triplicate, and the specificity of the reaction was determined by melting curve analysis at the dissociation stage. The relative quantitative method was used for quantitative analysis. The calibrator was the averaged $\Delta \mathrm{Ct}$ from untreated tissue. The endogenous control was glyceraldehyde 3phosphate dehydrogenase (GAPDH).

\section{Western Blots}

Cells were harvested and lysed in RIPA buffer and Protease Inhibitor Cocktail (Sigma, St. Louis, MO). Protein extracts were separated by sodium dodecyl sulfate-polyacrylamide gel electrophoresis (SDSPAGE), followed by transfer to polyvinylidene fluoride membranes (Bio-Rad). Membranes were incubated with phospho-GSK3B, GSK3B (Santa Cruz Biotechnology Inc., Santa Cruz, CA), ATK, phospho-AKT (Abcam, Cambridge, UK), phospho-p38 (Cell Signaling Technology, Danvers, MA, USA), antibodies in Trisbuffered saline, Tween 20 buffer with 5\% Bovine Serum Albumin in Tris-buffered saline with $0.1 \%$ Tween-20, followed by incubation with horseradish-peroxidase-conjugated secondary antibody (Santa Cruz Biotechnology Inc.). Immunoreactive bands were visualized using the Chemiluminescent Substrate Kit (Thermo Fisher Scientific).

\section{Results}

\section{Long-term, Whole Heart Explant}

Canonical cardiomyocyte culture media used in the maintenance of cardiomyocyte monolayers contains several growth factors together with fetal bovine serum (Base+FBS). However, under these conditions, explanted neonatal hearts rapidly accumulated double strand DNA damage and underwent coagulative necrosis and cell death due to insufficient access to nutrients and growth factors, as early as 3 days after the initiation of culture (Figure 1A). Replacing FBS with probumin ( $2 \%$ albumin), as a source of protein, plus the addition of $50 \mathrm{ng} / \mathrm{mL}$ rNRG-1 (Base $+\mathrm{P}+\mathrm{N}$ ) was sufficient to maintain DNA integrity, and cardiomyocyte function and structure 

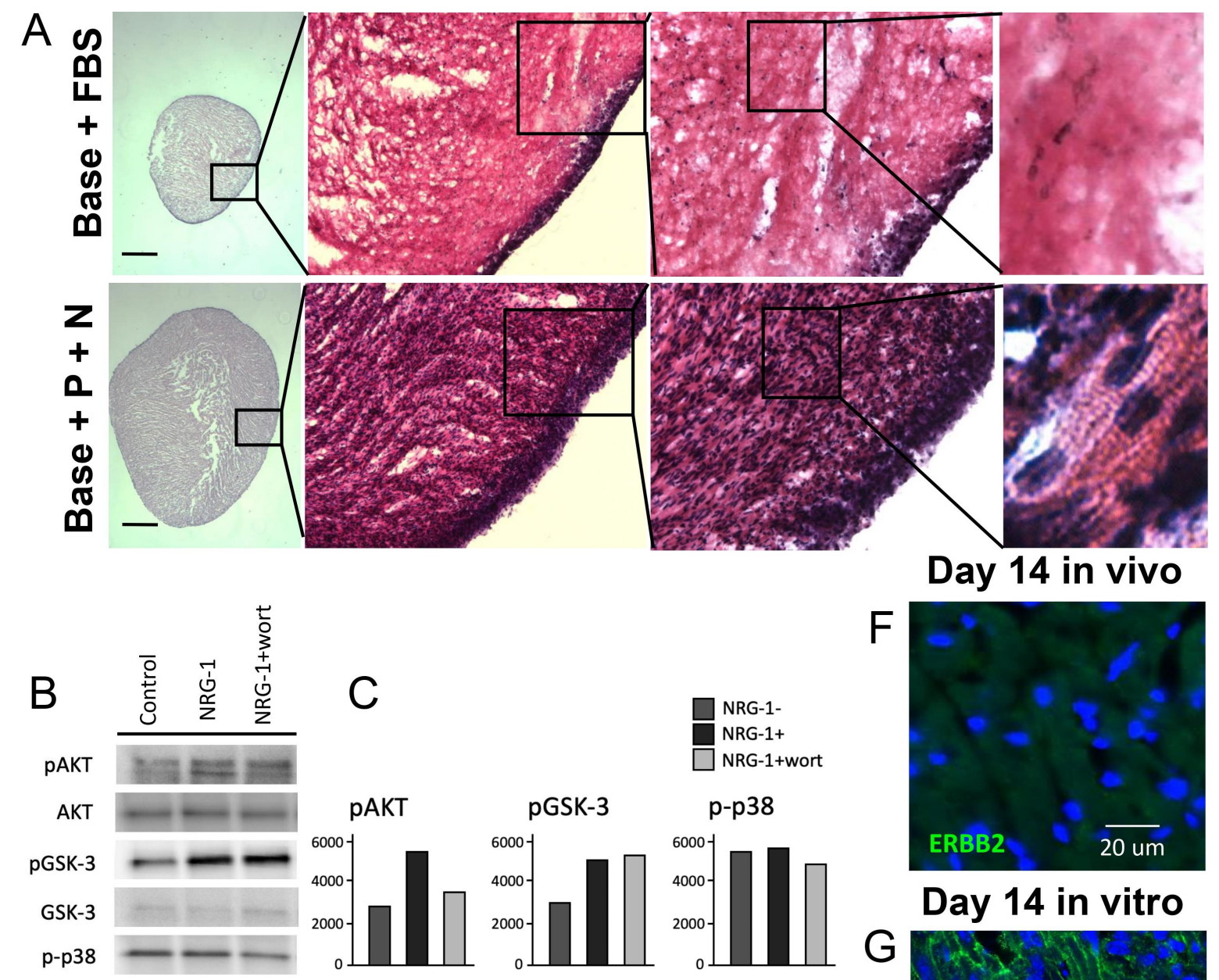

\section{Base + FBS}
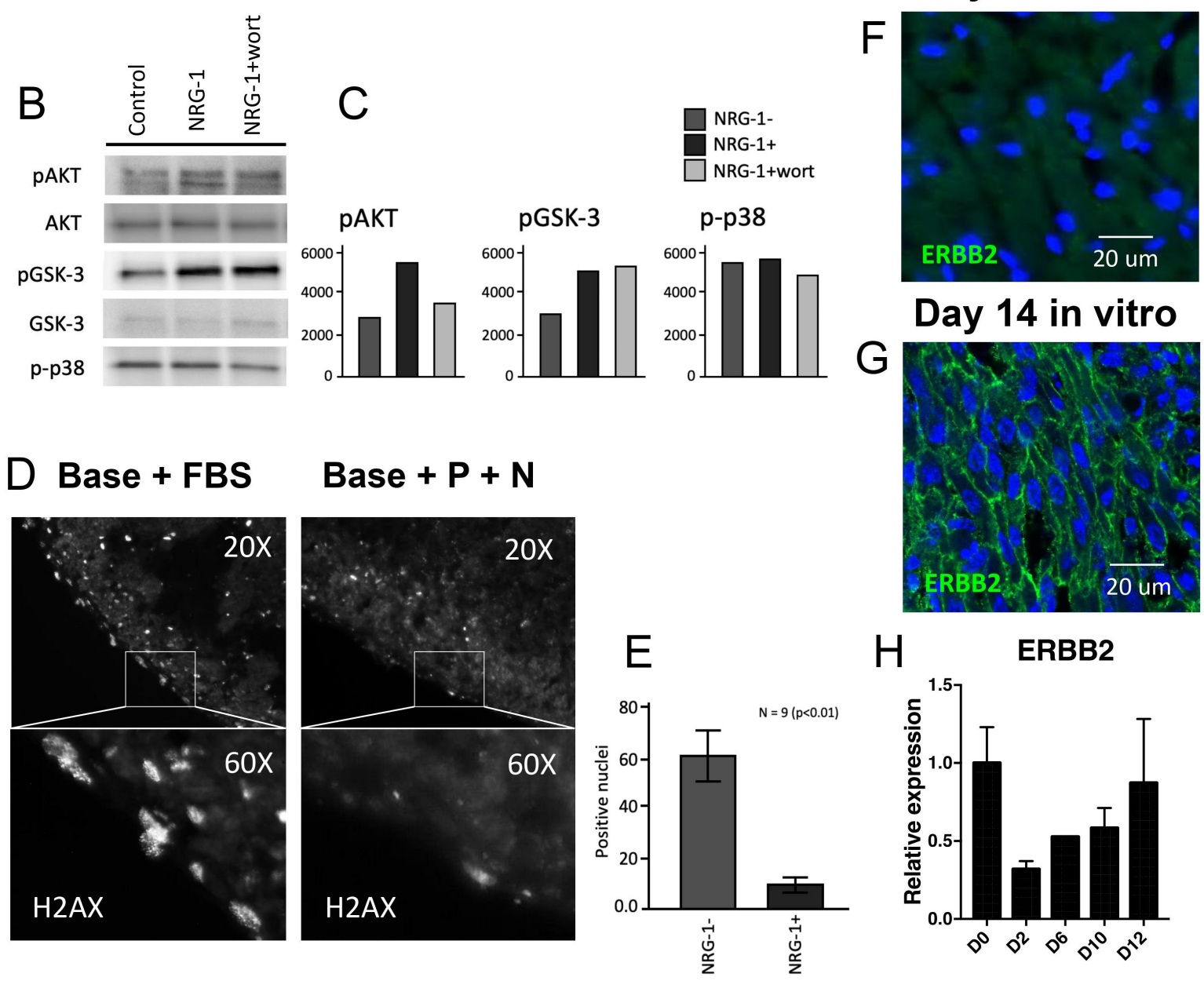

$\mathrm{H}$

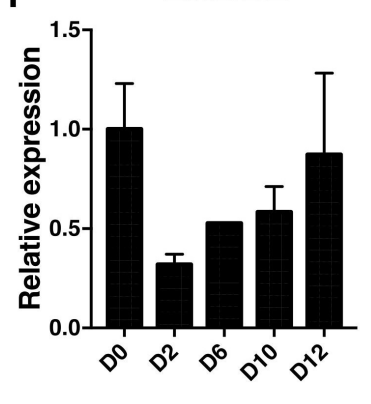

Figure 1. A novel ex vivo culture method containing rhNRG-1 can maintain structural, cellular and signalling properties in neonatal mouse heart explants. Explanted neonatal hearts rapidly accumulate double stranded DNA damage and undergo coagulative necrosis soon after plating in canonical cardiomyocyte culture media (Base + FBS) (A). Replacing FBS with probumin ( $2 \%$ albumin), together with $10 \mathrm{ng} / \mathrm{mL} r N R G-1$ (Base $+P+N)$ maintains DNA integrity, cardiomyocyte function and structure for greater than 21 days in culture (A). Phosphorylation of AKT and the serine/threonine protein kinase GSK-3 was increased by NRG-1. In contrast, phosphorylation of $p 38$ MAP kinase signalling, was not altered by the addition of $r N R G-1$ at protein the protein level (B) quantified in (C). H2AX immunofluorescence showed a significant reduction in DNA damage in $r N R G-1$ treated explants compared to controls $(D, E)$. Immunostaining $(F, G)$ and $q R T$-PCR $(H)$ showed that, in the presence of $r N R G-1$, the expression of ErbB2 on cardiomyocytes was maintained at high levels during long-term culture (12-14 days). 
for $>21$ days in culture (Figure 1A). Histologic evaluation of cardiomyocytes showed intact nuclei and sarcomeres, indicative of healthy, viable cells. Indeed, $>75 \%$ of hearts cultured in the presence of rNRG-1 retained a (non-coordinated) beating phenotype for up to 14-days following harvest (Supplemental video 1).

We next evaluated the mechanisms contributing to tissue survival in the cardiac cultures. rNRG-1 promoted anti-apoptotic and antinecrotic signaling at early time-points. Figure $1 \mathrm{~B}$ and $1 \mathrm{C}$ show that by day 3 , enhanced Pi3K/AKT signaling was evident, which was sensitive to the Pi3K inhibitor, wortmannin. Furthermore, phosphorylation (deactivation) of the serine/threonine protein kinase GSK-3 was increased by rNRG-1, an effect that was not blocked by wortmannin, as expected. In contrast, phosphorylation of p38 MAP kinase signaling, which can inhibit cardiomyocyte proliferation, was not affected by the addition of rNRG-1 (Figure 1B and 1C). We observed a significant reduction in double strand DNA damage in rNRG-1 treated explants compared to controls (-NRG1 $60 \pm 12$ cells per panel vs. +NRG1 $8 \pm 3, \quad \mathrm{p}<0.01)$ based on $\mathrm{H} 2 \mathrm{AX}$ immunofluorescence (Figure 1D and 1E). Interestingly, the expression of ErbB2, the tyrosine kinase receptor for NRG-1, declines in vivo within the first 7 postnatal days ${ }^{[15]}$ and this decay coincides with a loss of innate regenerative ability ${ }^{[6]}$. In the salamander (axolotl), NRG-1 protein is abundant in the regenerative blastema, but both NRG-1 and ErbB2 expression is reduced upon denervation, suggesting that peripheral nerves support a positive- feedback loop that sustains NRG-1 and ErbB2 expression ${ }^{[17,18]}$. We tested if exposure of explant neonatal hearts to rNRG-1 would similarly maintain expression of ErbB2 on cardiomyocytes. We observed that in the presence of rNRG-1, ErbB2 was maintained at high levels during long-term (14 days) in vitro culture compared to in vivo counterparts (Figure $1 \mathrm{~F}-\mathrm{H}$ ). This result suggests that supplementing explant media with rNRG-1 is necessary and sufficient to maintain robust ErbB2 expression in the absence of cardiac sympathetic nerves, a situation that would facilitate cardiomyocyte responsiveness to the pro-survival and anti-apoptotic effects of NRG-1 ${ }^{[19,20]}$

\section{Activation of Ex Vivo Injury Response}

Recent reports in zebrafish and mice suggest that NRG-1 treatment in vivo acts as a potent mitogen, triggering cardiomyocyte proliferation and cardiac repair ${ }^{[11,21]}$. In neonatal heart explant cultures treated with rNRG-1, we did not observe analogous cardiomyocyte proliferation, despite robust activation of pro-survival and anti-apoptotic signaling (Figure 1B-E). In the presence of rNRG1 hearts remain viable for $>21$ days; however, these injuries fail to initiate robust mitosis within the myocardium. Indeed, cellular proliferation, as determined by 5-ethynyl-2'-deoxyuridine (EdU) ${ }^{[22]}$ incorporation, is minimal at day 3 post-injury $(21 \pm 11 \mathrm{EdU}+$ cells; $\mathrm{n}=4$ hearts, 3 tissue sections from each) and is exclusively limited to the epicardial layer surrounding the heart (Figure 2A).

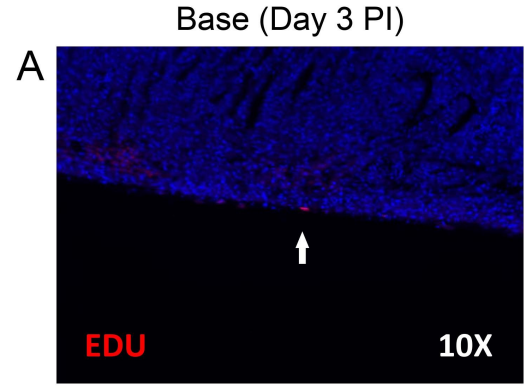

Base + NWB (Day $3 \mathrm{PI})$

B

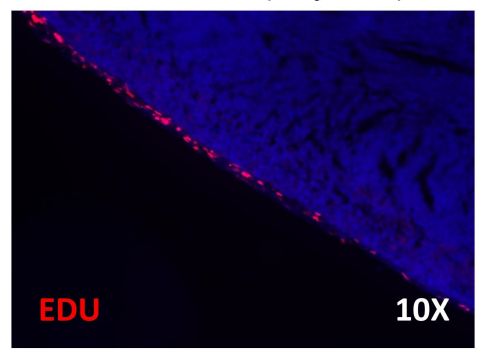

C

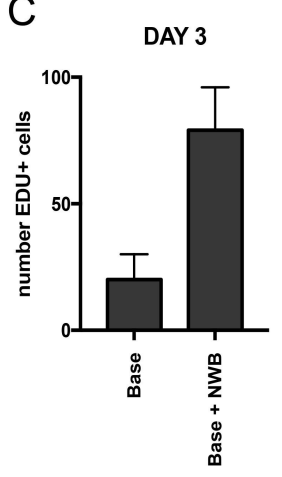

Base + NWB (Day $3 \mathrm{PI})$

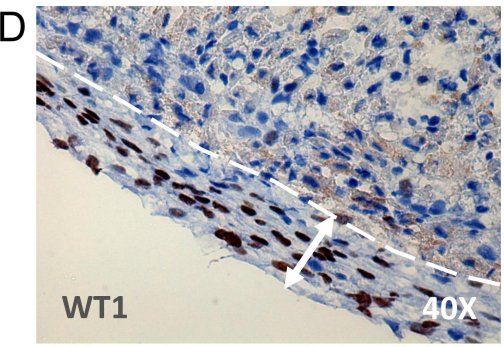

2-Day old mouse heart

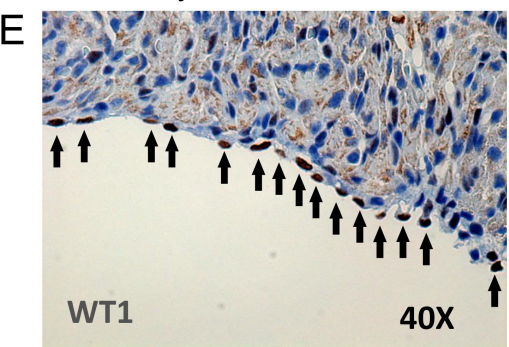

G
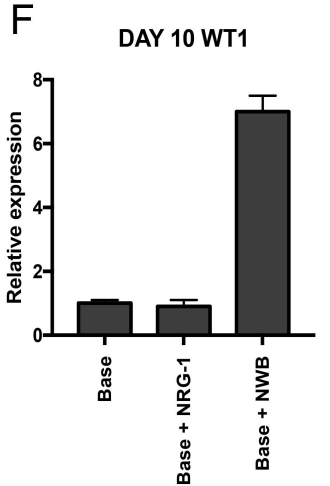
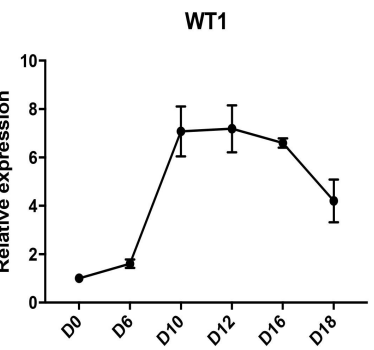

Figure 2. Epicardial cell activation and proliferation can be initiated by the addition of Wnt/BMP signalling in whole, cultured murine heart explants. 5-ethynyl-2'-deoxyuridine (EdU) staining shows limited epicardial cell proliferation when explanted hearts are cultured in $r N R G$ - 1 alone $($ Base $+P+N)$ for 3 days (A). In the presence of Wnt3a, BMP-4 and RA (Base $+N W B$ ), explants showed robust epicardial activation and proliferation at day 3 as indicated by $E D U$ staining $(B, C)$ and immunohistochemistry against Wt1 (D) compared to a 2-day old freshly isolated neonatal heart (E). qRT-PCR identified epicardial Wt1 expression peaked at day 10 in culture (Base $+N W B$ ) before gradually declining towards baseline $(F, G)$. 
The epicardium is substantively involved in zebrafish cardiac regeneration and supports cardiomyocyte proliferation early in development. Therefore, we sought to assess if enhanced epicardial activation in murine neonatal cardiac cultures promotes myocyte proliferation $^{[23,24]}$. Epicardial cell fate determination, differentiation and migration from the proepicardial organ during embryogenesis is coordinated through the regulated expression of growth factors that are under tight temporal control ${ }^{[25,26]}$. Wnt $/ \beta$-catenin signaling plays an important role during vertebrate heart development, and is reactivated in response to cardiac injury ${ }^{[27]}$. Following acute ischemic injury, the epicardium is activated, organ-wide, in a Wnt-dependent manner. Cells subsequently proliferate and undergo epithelialmesenchymal transition ${ }^{[28,}{ }^{29]}$. Both epicardial maturation and cardiomyocyte specification require BMP-4 ${ }^{[30-32]}$, which together with the morphogenetic factor Retinoic acid (RA), contributes to normal cardiac development during embryogenesis. Together Wnt3a, BMP-4 and RA constitute a potent group of growth factors that orchestrate epicardial and myocardial development and response to injury ${ }^{[33]}$. We therefore, supplemented our MM with Wnt3a (25 $\mathrm{ng} / \mathrm{mL})$, BMP-4 $(100 \mathrm{ng} / \mathrm{mL})$ and RA $(4 \mu \mathrm{M})(\mathrm{NWB})$. By day 3 this treatment produced robust epicardial activation and proliferation (-NWB: $21 \pm 9$ cells vs. + NWB: $78 \pm 17$ cells; $\mathrm{P}<0.05$ ), Figure $2 \mathrm{~A}-\mathrm{E})$. Epicardial $W t 1$ expression peaked at day 10 in culture before gradually declining (Figure $2 \mathrm{~F}$ and $2 \mathrm{G}$ ).

\section{Recellularization of Myocardial Injury}

While removing the heart from the neonatal mouse might constitute "injury" we reasoned that a direct physical injury to the ventricular myocardium might be necessary to assess cardiac repair and myocardial proliferation in response to $\mathrm{rNRG}-1$ in explants. Therefore, we mechanically injured the free ventricular wall by introducing a small cut into the myocardium. The cut opens to form a wedge-shaped injury (Figure $3 \mathrm{~A}$ and $3 \mathrm{~B}$ ). When the ventricular free wall of explants is mechanically injured and the epicardium activated, we observed a robust recellularization of the injury site. Within the first three days the injury is filled with extracellular matrix, which becomes a substrate for an influx of proliferative migratory epicardial cells (Figure 3C-E). By day 21 the injury site has become completely recellularized (Figure $3 \mathrm{~F}$ and $3 \mathrm{G}$ ), with little or no evidence of fibrosis (Figure $3 \mathrm{H}$ ), resembling the in vivo regenerative process in neonate ${ }^{[6]}$.

Although cardiac injury proceeds in the presence of cardiomyocyte proliferation in vivo ${ }^{[6,11,21,23,34]}$ we did not observe cardiomyocyte mitosis within the myocardium in this ex vivo system. Rather, our data suggest that proliferation is restricted exclusively to the epicardium and cells located within the injury site itself (Figure 3I). However, this observation does not preclude the possibility that cardiomyocytes migrate to the injury in response to epicardial tropic signaling (see below) ${ }^{[35]}$.

To confirm the epicardial origin of cells responsible for early recellularization of the injury, we utilized a transgenic reporter system to exclusively label $\mathrm{Wt}^{+}$epicardial cells. We crossed

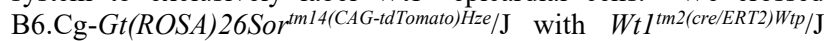
$\left(\right.$ Wt $\left.1^{\text {CreERT2/+}} ; \operatorname{Rosa} 26^{m T m G /+}\right)$ mouse strains. These mice harbor a targeted mutation of the Gt(ROSA)26Sor locus with a loxP-flanked "stop" cassette preventing transcription of a CAG promoter-driven red fluorescent protein variant (tdTomato), which is expressed following Wt1Cre-mediated recombination ${ }^{[36]}$ (Figure 3J). Breeding these transgenic mouse lines together, generated progeny where all tissues are tdTomato positive unless WT1 is expressed, at which point recombination results in permanent GFP expression. Uninjured, freshly isolated neonatal hearts are $\mathrm{dtTomato}^{+}$except for the single layer of $\mathrm{WT}^{+}$epicardial cells surrounding the entire ventricular myocardium (Figure $3 \mathrm{~K}$ ). When cultured in regeneration media (Base + NRG-1, Wnt3a, BMP4, RA), $\mathrm{WT} 1^{+} / \mathrm{GFP}^{+}$cells are
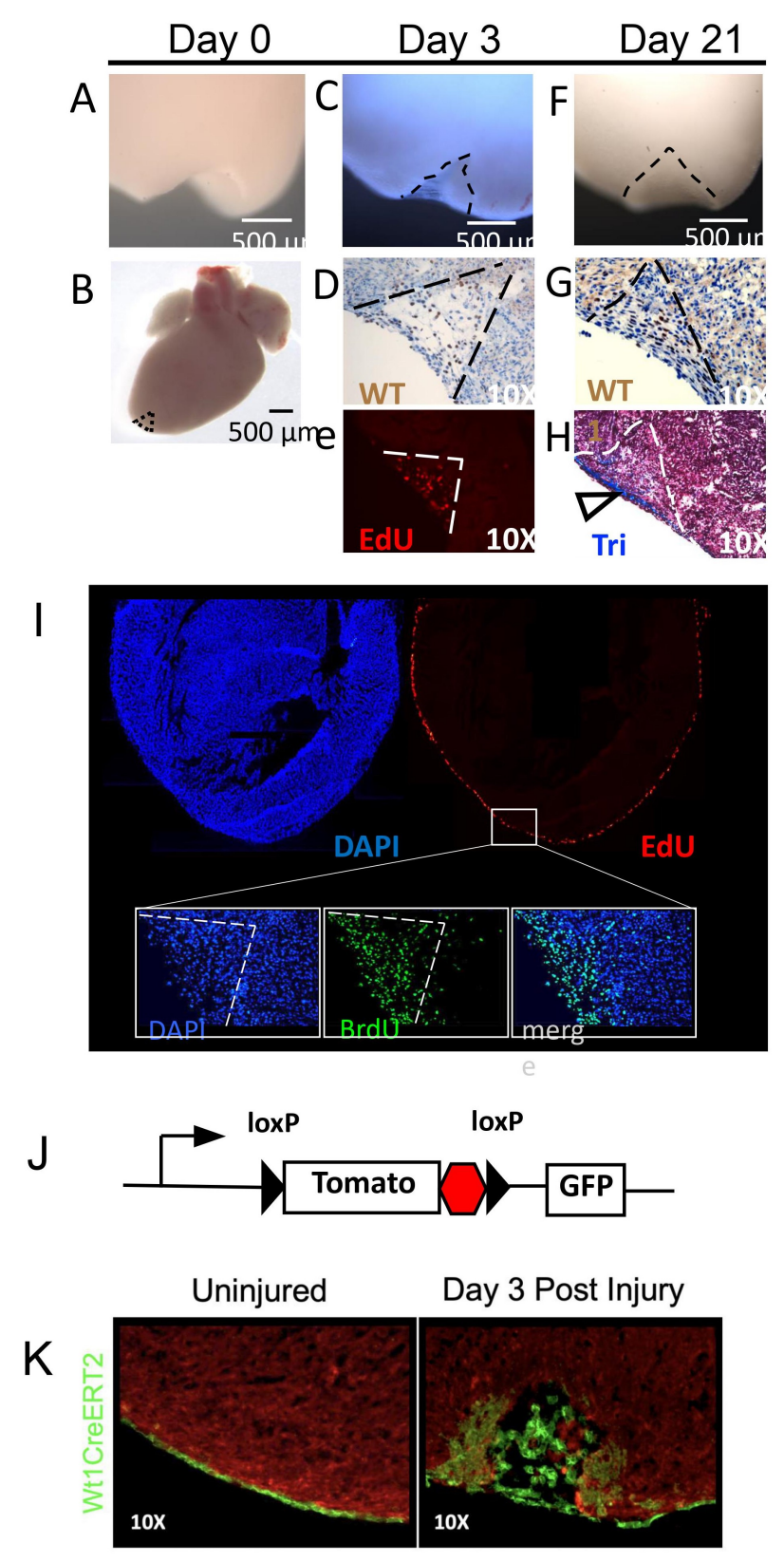

Figure 3. Mechanical injury to cardiac explants leads to epicardial cell proliferation and migration into the site of injury. To investigate the regenerative potential of neonatal explanted hearts a small cut was introduced into the left ventricular free wall at the apex $(A, B)$. Within three days post injury, while in culture (Base $+N W B$ ), the injury site fills with extracellular matrix $(C)$ and an influx of proliferative cells as indicated by immunohistochemistry (D) and EdU staining (E). Complete recellularization of the site was observed by day $21(F, G)$ with limited evidence of fibrosis (arrowhead) as indicated by Masson's Trichome immunohistochemistry (H). Immunostaining revealed that cellular proliferation is exclusive to epicardial cells surrounding the heart (EdU) and to cells localized within injury site (BrdU) (I). To confirm the epicardial origin of cells responsible recellularization of the injury we utilized a transgenic reporter system to exclusively label $\mathrm{Wt}^{+}{ }^{+}$epicardial cells $(J)$. In this model all cells are red with the exception of those of epicardial origin, which recombine the "stop" cassette and express GFP (K). Upon injury and ex vivo culture (Base $+N W B$ ) GFP + cells can be seen populating the site of injury by day $3(K)$, confirming an epicardial lineage. 
found within the site by day 3 post-injury (Figure $3 \mathrm{~K}$ ), confirming their epicardial origin. These cells also re-express the embryonic transcription factor TBX18 suggestive of immature cardiomyoblast formation (Supplemental Figure 1). Despite a robust initial recellularization by $\mathrm{WT}^{+}$epicardial cells, GFP signal is progressively lost within the injury between day 12-21 (data not shown), suggesting that the primary cellular influx is replaced by an, as-of-yet unidentified, non-epicardial cellular source. Our data support the consensus within the field that epicardial cells do not differentiate directly into cardiomyocytes, but rather play an instructive role, potentially establishing a suitable cellular environment for cardiomyoblasts to repair. Indeed, our data promote a hypothesis where cardiomyocytes disassemble their sarcomeres ${ }^{6}$, becoming circular rather than elongated, and migrate into and populate the injury from the surrounding myocardium (Supplemental Figure 2).

\section{Cellular Source of Injury Responsive Cells.}

Following an initial influx of epicardial cells, WT1 surface expression is gradually lost as the repair matures past day 12 (Figure $2 \mathrm{G}$ and $3 \mathrm{G}$ ). This loss in WT1 antigen expression coincides with a los of WT1;GFP expression, suggesting the elimination of epicardial-derived cells from the site of injury. At this time, immunofluorescence analysis indicates that expression of the transcription factors GATA4 and Nkx2-5 is reactivated within the proliferating population, (Figure 4A-D) and qPCR (Figure 4E and $4 \mathrm{~F}$ ), indicative of cardiomyocyte differentiation, but no increase in the late cardiomyocyte differentiation factor Tbx 5 or the cardiac stem cell marker c-Kit was observed (Figure $4 \mathrm{G}$ and $4 \mathrm{H}$ ). This result suggests that putative cardiac stem cells do not contribute to a denovo population of cardiomyocytes within the lesion.

Our preliminary data suggest a potential clue as to the source of cardiomyocytes. The FUCCI system marks specfic cell cycle stages within live cells ${ }^{[37]}$. A cell in the G1 phase of cell cycle expresses a red nuclear reporter, which can be visualized by epifluroescence histology (Supplemental Figure 3). In our experiments, by day 21 following injury, the site is resolved and closely resembles the surrounding myocardium (Supplemental Figure 3, DAPI). However, by using FUCCI mice we see that the entire subepicardium is populated with cardiomyocytes in a pre-mitotic state in G1 (Supplemental Figure 3, G1). These cells are restricted to the subepicardium and they surround the site of injury, yet are not represented in the myocardium adjacent to the endocardium, in the epicardium or within the injury itself (Supplemental Figure 3, Merge).

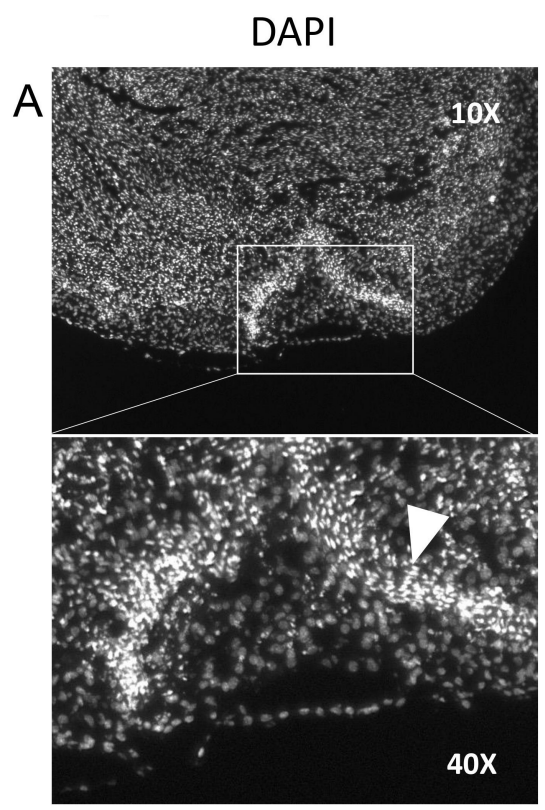

NKX2-5
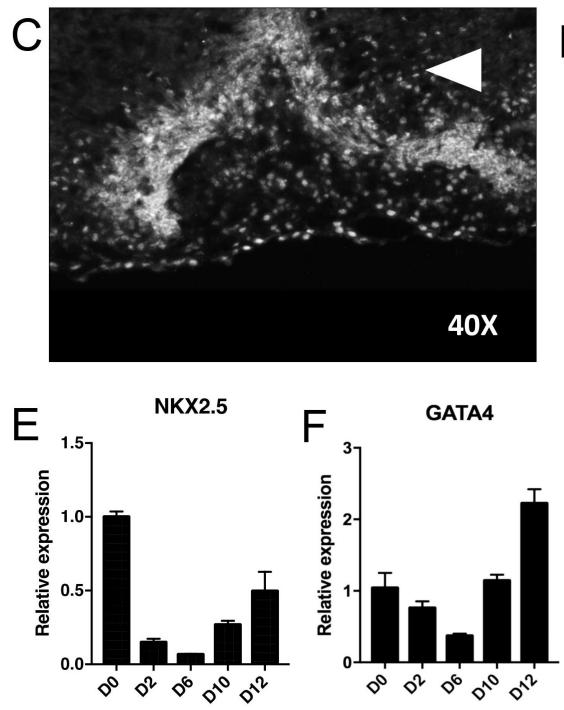

EdU

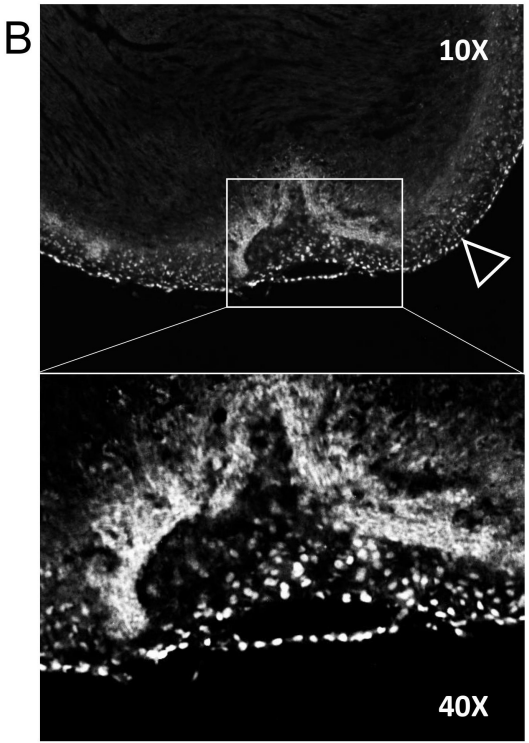

GATA4
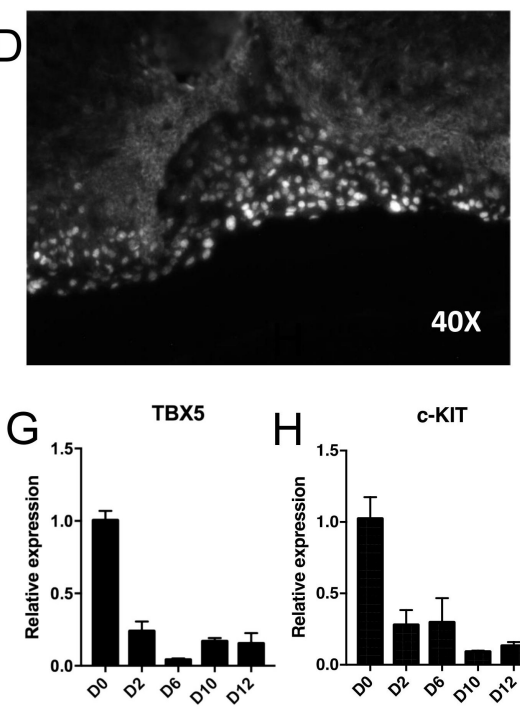

Figure 4. Cells expressing embryonic transcription factors Nkx2-5 and GATA4 evolve within the site of recellularization in an ex vivo model of mammalian cardiac regeneration. After 12 days in culture (Base+NWB) WTI expression is lost from the injury site. Within the proliferating population $(A, B)$ transcription factors NKX2-5 (C) and GATA4 (D) are reactivated as indicated by immunostaining. The gene expression profile of NKX2-5 (e) and GATA4 (F) demonstrates the opposite temporal profile compared to Wt 1 expression, demonstrating an increase from day 10 to day 12 , which is indicative of cardiomyocyte differentiation. TBX5 (G) and c-kit $\left.H_{(}\right)$RNA levels do not follow the same trajectory, but rather are immediately reduced suggesting putative cardiac stem cells are not involved with this regenerative response. 


\section{Discussion}

We tested the ability of recombinant NRG-1 to rescue regeneration following injury to the apex of neonatal hearts, ex vivo. Unlike when parasympathetic denervation in reversed in vivo with exogenous administration of rNRG-1 ${ }^{[11]}$, rNRG-1 was not sufficient to induce regeneration in cardiac explants, ex vivo. However, epicardial cell activation via Wnt and BMP signaling, in combination with NRG-1, was necessary and sufficient to restore the endogenous regenerative program lost due to the denervation of explanted hearts. Sympathetic nerve-derived Wnt mediates repair programs in several animal models ${ }^{[27,38,39]}$, plays an important role during vertebrate heart development, and is re-activated in response to cardiac injury ${ }^{[27]}$. Following acute ischemic injury, the epicardium is activated, organwide, in a Wnt-dependent manner. Cells subsequently proliferate and undergo epithelial-mesenchymal transition ${ }^{[28,29]}$. Both epicardial maturation and cardiomyocyte specification require BMP-4 $4^{[30-32]}$, which together with the morphogenetic factor Retinoic acid (RA), contributes to normal cardiac development during embryogenesis. RA has both early patterning roles and subsequent mitogenic roles $^{[40,41]}$. Together Wnt3a, BMP-4 and RA constitute a potent group of growth factors that orchestrate epicardial and myocardial development and response to injury ${ }^{[33]}$.

The essential role that peripheral nerves play in tissue regeneration is well-established across a wide array of species and tissues ${ }^{[18]}$, but only recently has the role of cardiac nerves in mammalian cardiac tissue regeneration been explored ${ }^{[11,12,42-49]}$. Having now established a link between cardiac nerves, heart regeneration and disease progression, understanding the mechanism of nerve-mediated cardiac responses to injury is needed. Again, we looked to established models for clues into the signaling pathways and cellular contribution during an injury response. NRG-1 plays a critical role in a broad range of tissue homeostasis and regeneration models $s^{[9,14,17,19-21,50,51]}$, it is essential for nerve-dependent axolotl limb regeneration ${ }^{[14]}$ and is an injury-induced cardiomyocyte mitogen for the endogenous heart regeneration in zebrafish ${ }^{[18]}$. Understanding the role of NRG-1, and other putative nerve-dependent growth factors, in mammalian cardiac regeneration is confounded by in vivo complexity. To make it easier to address the mechanisms underlying cardiac repair, we developed an ex vivo culture system where explanted neonatal hearts maintain their three-dimensional structure and perinatal regenerative ability ${ }^{[6]}$. Despite the absence of the cardiac nerves that are required for homeostasis and regeneration ${ }^{[8,9,48]}$, we maintained neonatal hearts for more than 21 days under defined ex vivo conditions by the addition of rNRG-1. While rNRG-1 alone does not enable cardiac repair of the injured neonatal explant, as previously described in related models ${ }^{[11,20]}$, NRG-1 increased Pi3K/AKT and decreased GSK-3 activation, reduced double strand DNA damage, enhanced cardiomyocyte survival in long-term culture and maintained high levels of expression of ERBB2 on the surface of cardiomyocytes, which has been previously shown to trigger mammalian heart regeneration by promoting cardiomyocyte dedifferentiation and proliferation ${ }^{[12]}$.

Wnt3a, BMP-4 and RA were needed, in addition to rNRG-1, to induce cardiac regeneration ex vivo. Sympathetic nerve-derived Wnt mediates repair programs in several animal models ${ }^{[27,38,39]}$, although the mechanism of repair is incompletely understood. Interestingly, treatment of human iPSCs with Wnt3a and BMP-4 followed by Wnt inhibition causes an increase in biologically functional cardiomyocytes, suggesting that BMP- 4 and $\mathrm{Wnt} / \beta$-catenin signaling pathways play a major role in the production new cardiomyocytes following cardiac injury ${ }^{[30]}$. Both factors are critical during embryogenesis and in established models of tissue regeneration ${ }^{[52]}$, and provide insight into the mechanisms of mammalian cardiac regeneration that would have been difficult to identify using an in vivo model. Wnt/ß-catenin signaling plays a key role in regeneration of the heart ${ }^{[27,28,53]}$, and certain other tissues ${ }^{[38,39,54]}$. In the heart, this reparative effect of $\mathrm{Wnt} / \mathrm{B}$-catenin signaling may function through the activtion of epicardial cells ${ }^{[28,41]}$
The epicardium, a single-cell, thick mesothelial layer surrounding the heart, has a key regulatory role in the regenerative process in competent species such as zebrafish and the neonatal mouse ${ }^{[2,4,5,55]}$. In combination with $\mathrm{Wnt} / \mathrm{B}$-catenin signaling, retinoic acid represents a robust co-activator and mitogen of both epicardium and myocardial cells ${ }^{[40,41,55,56]}$. Following activation and epicardial endothelial to mesenchymal transition, the injury response in cardiac explants can be further enhanced with the removal of Wnt3a and

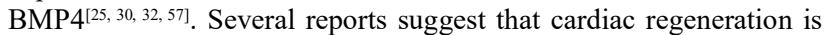
mediated through the proliferation of cardiomyocytes ${ }^{[58,59]}$, however, our data do not support that model in the ex vivo heart, at least outward of the injury site. Our data agree with published reports suggesting that epicardial cells do not transdifferentiate to generate de-novo cardiomyocytes in the post-embryonic heart. Rather these data suggest that resident cardiomyocytes dissesemble their sarcomeres and cytoplasmic structure and migrate to populate the site of injury (Supplemental Figure 2) ${ }^{[15]}$. Interestingly, we found no evidence of cardiomyocyte proliferation within the injury site by either EdU or Phospho-histone-H3 immunofluorescence. This finding underscores the complexity of the regenerative process and supports further studies focusing not only on the biochemical mechanisms, but also the temporal cellular dynamics within the injury and in the surrounding tissue.

Our preliminary data suggest a potential clue as to the source of cardiomyocytes. The FUCCI system marks specfic cell cycle stages within live cells where a cell in the G1 phase of cell cycle expresses a red nuclear reporter ${ }^{[37]}$. In our experiments, by day 21 following injury, the site is resolved and closely resembles the surrounding myocardium However, by using FUCCI mice we see that the entire subepicardium is populated with cardiomyocytes in a pre-mitotic state in G1. These cells are restricted to the subepicardium and they surround the site of injury, yet are not represented in the myocardium adjacent to the endocardium, in the epicardium or within the injury itself.

Wnt3a and Bmp4 signaling activate specific, non-overlapping genes in cardiac progenitors with Nkx2-5 expression controlled by Wnt/Bcatenin, and Gata4 controlled by BMP signaling ${ }^{[57]}$. In murine models, genetic lineage-tracing studies indicate that the proepicardium originates from Nkx2-5- and ISL1-expressing lateral plate mesoderm progenitors ${ }^{[60]}$. ISL1, a marker of the secondary heart field, remained negative throughout the ex vivo regenerative process (data not shown). Several studies have reported that the epicardium is derived from $\mathrm{Nkx} 2-5^{+}$progenitors ${ }^{[61]}$ and the fate of epicardial and myocardial cells bifurcate at this stage. As a consequence, epicardial cells do not contribute to neo-myogenesis in the post-embryonic mammalian heart. Our data support this argument as no cardiomyocytes within injury sites expressed GFP or EdU. Rather, at approximately day 10 of culture, the fully recellularized injury began to lose the founding population of cells (Supplemental Figure 4a). These cells appear to be replaced by resident cardiomyocytes that migrate from the neighboring myocardium (Supplemental Figure 2). Once the injury resolves it was difficult to identify the site by histological methods. However, a vestige of the injury can be resolved by identifying non-specific auto-fluorescence (Supplemental Figure 4B). This feature together with a subtle concave indentation in the ventricular wall represents a signature for the identification of former injury sites. These sites are populated with cardiac troponin ${ }^{+}\left(\mathrm{cTnT}^{+}\right)$cells. However, rather than having the well-defined sarcomeric structure characteristic of adjacent cardiomyocytes, these cells demonstrate a rounded phenotype with disassembled sarcomeres as previously described in the regenerating apex of neonatal mouse hearts in vivo ${ }^{[6,62]}$ (Supplemental Figure 4C). The mechanisms driving this migration and maturation process are currently unresolved, however, a similar, distinct bilayer of cardiomyocytes demonstrating differing regenerative potential was recently seen in zebrafish ${ }^{[63]}$. We speculate that this subepicardial layer represents a pool of injury-responsive cells within the myocardium, although further work will be required to advance this hypothesis. 
The signaling pathways activated in response to injury and the mechanisms by which these signals activate the epicardium and drive regeneration are currently unknown. This report provides a novel and much-needed platform from which to address these important questions. Understanding the cell-intrinsic and extrinsic mechanisms governing regeneration of the neonatal murine heart can illuminate the fixed and flexible components of a cellular and molecular response to cardiac injury ${ }^{[64]}$. Such knowledge is critical to understanding the current limitations and future potential for repair in the injured adult human heart.

\section{References}

1. Benjamin EJ, Blaha MJ, Chiuve SE, Cushman M, Das SR, Deo R, de Ferranti SD, Floyd J, Fornage M, Gillespie C, Isasi CR, Jimenez MC, Jordan LC, Judd SE, Lackland D, Lichtman JH, Lisabeth L, Liu S, Longenecker CT, Mackey RH, Matsushita K, Mozaffarian D, Mussolino ME, Nasir K, Neumar RW, Palaniappan L, Pandey DK, Thiagarajan RR, Reeves MJ, Ritchey M, Rodriguez CJ, Roth GA, Rosamond WD, Sasson C, Towfighi A, Tsao CW, Turner MB, Virani SS, Voeks JH, Willey JZ, Wilkins JT, Wu JH, Alger HM, Wong SS, Muntner P, American Heart Association Statistics C and Stroke Statistics S. Heart Disease and Stroke Statistics-2017 Update: A Report From the American Heart Association. Circulation. 2017;135 (10):e146e603.

2. Masters $M$ and Riley PR. The epicardium signals the way towards heart regeneration. Stem Cell Res. 2014;13 (3 Pt B):683-92.

3. Mercer SE, Odelberg SJ and Simon HG. A dynamic spatiotemporal extracellular matrix facilitates epicardial-mediated vertebrate heart regeneration. Dev Biol. 2013;382 (2) :457-69.

4. van Wijk B, Gunst QD, Moorman $\mathrm{AF}$ and van den Hoff MJ. Cardiac regeneration from activated epicardium. PLoS One. 2012;7(9): :e44692.

5. Wang J, Cao J, Dickson AL and Poss KD. Epicardial regeneration is guided by cardiac outflow tract and Hedgehog signalling. Nature. 2015; 522(7555):226-230.

6. Porrello ER, Mahmoud AI, Simpson E, Hill JA, Richardson JA, Olson EN and Sadek HA. Transient regenerative potential of the neonatal mouse heart. Science. 2011; 331(6020):1078-80.

7. Ye L, D'Agostino G, Loo SJ, Wang CX, Su LP, Tan SH, Tee GZ, Pua CJ, Pena EM, Cheng RB, Chen WC, Abdurrachim D, Lalic J, Tan RS, Lee TH, Zhang J and Cook SA. Early Regenerative Capacity in the Porcine Heart. Circulation. 2018;138:2798-2808.

8. Zhu W, Zhang E, Zhao M, Chong Z, Fan C, Tang Y, Hunter JD, Borovjagin AV, Walcott GP, Chen JY, Qin G and Zhang J. Regenerative Potential of Neonatal Porcine Hearts. Circulation. 2018; 138(24):2809-2816.

9. Bergmann O, Bhardwaj RD, Bernard S, Zdunek S, BarnabeHeider F, Walsh S, Zupicich J, Alkass K, Buchholz BA, Druid H, Jovinge $\mathrm{S}$ and Frisen J. Evidence for cardiomyocyte renewal in humans. Science. 2009; 324(5923):98-102.

10. Aikawa T, Naya M, Obara M, Oyama-Manabe N, Manabe O, Magota K, Ito YM, Katoh C and Tamaki N. Regional interaction between myocardial sympathetic denervation, contractile dysfunction, and fibrosis in heart failure with preserved ejection fraction: (11)C-hydroxyephedrine PET study. Eur J Nucl Med Mol Imaging. 2017; 44(11):1897-1905.

11. Mahmoud AI, O'Meara CC, Gemberling M, Zhao L, Bryant DM, Zheng R, Gannon JB, Cai L, Choi WY, Egnaczyk GF, Burns CE, Burns CG, MacRae CA, Poss KD and Lee RT. Nerves Regulate Cardiomyocyte Proliferation and Heart Regeneration. Dev Cell. 2015; 34(4):387-99.

12. White IA, Gordon J, Balkan W and Hare JM. Sympathetic Reinnervation Is Required for Mammalian Cardiac Regeneration. Circ Res. 2015; 117(12):990-4.

13. Farag M, Arif R, Raake P, Kreusser M, Karck M, Ruhparwar A and Schmack B. Cardiac surgery in the heart transplant recipient: Outcome analysis and long-term results. Clin Transplant. 2019; 33(10):e13709.

14. Wadugu B and Kuhn B. The role of neuregulin/ErbB2/ErbB4 signaling in the heart with special focus on effects on cardiomyocyte proliferation. American journal of physiology Heart and circulatory physiology. 2012; 302(11):H2139-47.

15. D'Uva G, Aharonov A, Lauriola M, Kain D, Yahalom-Ronen Y, Carvalho S, Weisinger K, Bassat E, Rajchman D, Yifa O, Lysenko M, Konfino T, Hegesh J, Brenner O, Neeman M, Yarden Y, Leor J, Sarig R, Harvey RP and Tzahor E. ERBB2 triggers mammalian heart regeneration by promoting cardiomyocyte dedifferentiation and proliferation. Nat Cell Biol. 2015; 17(5):627-38.

16. Yu W, Huang X, Tian X, Zhang H, He L, Wang Y, Nie Y, Hu S, Lin Z, Zhou B, Pu W, Lui KO and Zhou B. GATA4 regulates Fgf16 to promote heart repair after injury. Development. 2016; 143(6):936-49.

17. Farkas JE, Freitas PD, Bryant DM, Whited JL and Monaghan JR. Neuregulin-1 signaling is essential for nerve-dependent axolotl limb regeneration. Development. 2016;143(15):2724-31.

18. Farkas JE and Monaghan JR. A brief history of the study of nerve dependent regeneration. Neurogenesis (Austin). 2017; 4(1):e1302216

19. Fukazawa R, Miller TA, Kuramochi Y, Frantz S, Kim YD, Marchionni MA, Kelly RA and Sawyer DB. Neuregulin-1 protects ventricular myocytes from anthracycline-induced apoptosis via erbB4-dependent activation of PI3-kinase/Akt. J Mol Cell Cardiol. 2003;35(12):1473-9.

20. Rupert CE and Coulombe KL. The roles of neuregulin-1 in cardiac development, homeostasis, and disease. Biomark Insights. 2015; 10(Suppl 1):1-9.

21. Gemberling M, Karra R, Dickson AL and Poss KD. Nrg1 is an injury-induced cardiomyocyte mitogen for the endogenous heart regeneration program in zebrafish. Elife. 2015; 4:e05871.

22. Zeng B, Tong S, Ren X, Xia H. Cardiac cell proliferation assessed by EdU, a novel analysis of cardiac regeneration. Cytotechnology. 2016;68(4):763-70.

23. Schnabel K, Wu CC, Kurth T, Weidinger G. Regeneration of cryoinjury induced necrotic heart lesions in zebrafish is associated with epicardial activation and cardiomyocyte proliferation. PLoS One. 2011;6(4):e18503.

24. Zhou B, Ma Q, Rajagopal S, Wu SM, Domian I, Rivera-Feliciano J, Jiang D, von Gise A, Ikeda S, Chien KR, Pu WT. Epicardial progenitors contribute to the cardiomyocyte lineage in the developing heart. Nature. 2008;454(7200):109-13.

25. Bao X, Lian X, Hacker TA, Schmuck EG, Qian T, Bhute VJ, Han T, Shi M, Drowley L, Plowright A, Wang QD, Goumans MJ, Palecek SP. Long-term self-renewing human epicardial cells generated from pluripotent stem cells under defined xeno-free conditions. Nat Biomed Eng. 2016;1:0003.

26. Takeichi M, Nimura K, Mori M, Nakagami H, Kaneda Y. The transcription factors Tbx18 and $\mathrm{Wt1}$ control the epicardial epithelial-mesenchymal transition through bi-directional regulation of Slug in murine primary epicardial cells. PLoS One. 2013;8(2):e57829.

27. Ozhan $\mathrm{G}$ and Weidinger $\mathrm{G}$. Wnt/beta-catenin signaling in heart regeneration. Cell Regen (Lond). 2015;4:3.

28. Duan J, Gherghe C, Liu D, Hamlett E, Srikantha L, Rodgers L, Regan JN, Rojas M, Willis M, Leask A, Majesky M, Deb A. Wnt $1 / \beta$ catenin injury response activates the epicardium and cardiac fibroblasts to promote cardiac repair. EMBO J. 2012;31(2):429-42

29. von Gise A, Pu WT. Endocardial and epicardial epithelial to mesenchymal transitions in heart development and disease. Circ Res. 2012;110(12):1628-45.

30. Ren Y, Lee MY, Schliffke S, Paavola J, Amos PJ, Ge X, Ye M, Zhu S, Senyei G, Lum L, Ehrlich BE, Qyang Y. Small molecule Wnt inhibitors enhance the efficiency of BMP-4-directed cardiac differentiation of human pluripotent stem cells. J Mol Cell Cardiol. 2011;51(3):280-7.

31. Kang JO, Sucov HM. Convergent proliferative response and divergent morphogenic pathways induced by epicardial and endocardial signaling in fetal heart development. Mech Dev. 2005;122(1):57-65.

32. Witty AD, Mihic A, Tam RY, Fisher SA, Mikryukov A, Shoichet MS, Li RK, Kattman SJ, Keller G. Generation of the epicardial lineage from human pluripotent stem cells. Nat Biotechnol. 2014;32(10):1026-35.

33. Iyer D, Gambardella L, Bernard WG, Serrano F, Mascetti VL, Pedersen RA, Talasila A, Sinha S. Robust derivation of epicardium and its differentiated smooth muscle cell progeny from human pluripotent stem cells. Development. 2015;142(8):1528-41.

34. Zhao L, Borikova AL, Ben-Yair R, Guner-Ataman B, MacRae CA, Lee RT, Burns CG, Burns CE. Notch signaling regulates cardiomyocyte proliferation during zebrafish heart regeneration. Proc Natl Acad Sci U S A. 2014;111(4):1403-8.

35. Itou J, Oishi I, Kawakami H, Glass TJ, Richter J, Johnson A, Lund TC, Kawakami Y. Migration of cardiomyocytes is essential for heart regeneration in zebrafish. Development. 2012;139(22):4133-42. 
36. Muzumdar MD, Tasic B, Miyamichi K, Li L, Luo L. A global double-fluorescent Cre reporter mouse. Genesis. 2007;45(9):593605 .

37. Sakaue-Sawano A, Kurokawa H, Morimura T, Hanyu A, Hama H, Osawa H, Kashiwagi S, Fukami K, Miyata T, Miyoshi H, Imamura $\mathrm{T}$, Ogawa $\mathrm{M}$, Masai $\mathrm{H}$, Miyawaki A. Visualizing spatiotemporal dynamics of multicellular cell-cycle progression. Cell. 2008;132(3):487-98.

38. Soeda J, Mouralidarane A, Ray S, Novelli M, Thomas S, Roskams T, Diehl AM, Oben JA. The $\beta$-adrenoceptor agonist isoproterenol rescues acetaminophen-injured livers through increasing progenitor numbers by Wnt in mice. Hepatology. 2014;60(3):1023-34

39. Spiegel A, Shivtiel S, Kalinkovich A, Ludin A, Netzer N, Goichberg P, Azaria Y, Resnick I, Hardan I, Ben-Hur H, Nagler A, Rubinstein M, Lapidot T. Catecholaminergic neurotransmitters regulate migration and repopulation of immature human $\mathrm{CD} 34+$ cells through Wnt signaling. Nat Immunol. 2007;8(10):1123-31.

40. Kikuchi K, Holdway JE, Major RJ, Blum N, Dahn RD, Begemann $\mathrm{G}$, Poss KD. Retinoic acid production by endocardium and epicardium is an injury response essential for zebrafish heart regeneration. Dev Cell. 2011;20(3):397-404.

41. von Gise A, Zhou B, Honor LB, Ma Q, Petryk A, Pu WT. WT regulates epicardial epithelial to mesenchymal transition through $\beta$-catenin and retinoic acid signaling pathways. Dev Biol. 2011;356(2):421-31.

42. Chen J, Zheng S, Huang H, Huang S, Zhou C, Hou J, Jiang J, Wang $\mathrm{J}, \mathrm{Wu} \mathrm{W}$, Wang T. Mesenchymal stem cells enhanced cardiac nerve sprouting via nerve growth factor in a rat model of myocardial infarction. Curr Pharm Des. 2014;20(12):2023-9.

43. Pardanaud L, Pibouin-Fragner L, Dubrac A, Mathivet T, English I, Brunet I, Simons M, Eichmann A. Sympathetic Innervation Promotes Arterial Fate by Enhancing Endothelial ERK Activity. Circ Res. 2016;119(5):607-20.

44. Parisi V, Rengo G, Perrone-Filardi P, Pagano G, Femminella GD, Paolillo S, Petraglia L, Gambino G, Caruso A, Grimaldi MG, Baldascino F, Nolano M, Elia A, Cannavo A, De Bellis A, Coscioni E, Pellegrino T, Cuocolo A, Ferrara N, Leosco D. Increased Epicardial Adipose Tissue Volume Correlates With Cardiac Sympathetic Denervation in Patients With Heart Failure. Circ Res. 2016;118(8):1244-53.

45. Zaglia T, Milan G, Franzoso M, Bertaggia E, Pianca N, Piasentini E, Voltarelli VA, Chiavegato D, Brum PC, Glass DJ, Schiaffino S, Sandri M, Mongillo M. Cardiac sympathetic neurons provide trophic signal to the heart via $\beta 2$-adrenoceptor-dependent regulation of proteolysis. Cardiovasc Res. 2013;97(2):240-50.

46. Pan L, Tang J, Liu H, Cheng B. Sympathetic nerves: How do they affect angiogenesis, particularly during wound healing of sof tissues? Clin Hemorheol Microcirc. 2016;62(2):181-91.

47. Kreipke RE, Birren SJ. Innervating sympathetic neurons regulate heart size and the timing of cardiomyocyte cell cycle withdrawal. J Physiol. 2015;593(23):5057-73.

48. Jiang YH, Jiang P, Yang JL, Ma DF, Lin HQ, Su WG, Wang Z, Li X. Cardiac Dysregulation and Myocardial Injury in a 6Hydroxydopamine-Induced Rat Model of Sympathetic Denervation. PLoS One. 2015;10(7):e0133971.

Sakai K, Fukuda T, Iwadate K. Is the denervation or hyperinnervation of the cardiac sympathetic nerve in the subepicardium related to unexpected cardiac death? Cardiovasc Pathol. 2014;23(4):211-6.

50. Polizzotti BD, Ganapathy B, Walsh S, Choudhury S, Ammanamanchi N, Bennett DG, dos Remedios CG, Haubner BJ, Penninger JM, Kühn B. Neuregulin stimulation of cardiomyocyte regeneration in mice and human myocardium reveals a therapeutic window. Sci Transl Med. 2015;7(281):281ra45.
51. Parodi EM, Kuhn B. Signalling between microvascular endothelium and cardiomyocytes through neuregulin. Cardiovasc Res. 2014;102(2):194-204.

52. Hatzistergos KE, Takeuchi LM, Saur D, Seidler B, Dymecki SM, Mai JJ, White IA, Balkan W, Kanashiro-Takeuchi RM, Schally AV and Hare JM. cKit+ cardiac progenitors of neural crest origin. Proceedings of the National Academy of Sciences. 2015;112:13051-13056.

53. Xin M, Kim Y, Sutherland LB, Murakami M, Qi X, McAnally J, Porrello ER, Mahmoud AI, Tan W, Shelton JM, Richardson JA, Sadek HA, Bassel-Duby R, Olson EN. Hippo pathway effector Yap promotes cardiac regeneration. Proc Natl Acad Sci U S A. 2013;110(34):13839-44.

54. Wehner D, Cizelsky W, Vasudevaro MD, Ozhan G, Haase C, Kagermeier-Schenk B, Röder A, Dorsky RI, Moro E, Argenton F, Kühl M, Weidinger G. Wnt/ $\beta$-catenin signaling defines organizing centers that orchestrate growth and differentiation of the regenerating zebrafish caudal fin. Cell Rep. 2014;6(3):467-81.

55. Guadix JA, Ruiz-Villalba A, Lettice L, Velecela V, MuñozChápuli R, Hastie ND, Pérez-Pomares JM, Martínez-Estrada OM. Wt1 controls retinoic acid signalling in embryonic epicardium through transcriptional activation of Raldh2. Development. 2011;138(6):1093-7.

56. Brade T, Kumar S, Cunningham TJ, Chatzi C, Zhao X, Cavallero S, Li P, Sucov HM, Ruiz-Lozano P, Duester G. Retinoic acid stimulates myocardial expansion by induction of hepatic erythropoietin which activates epicardial Igf2. Development. 2011;138(1):139-48.

57. Klaus A, Müller M, Schulz H, Saga Y, Martin JF, Birchmeier W. Wnt/ $\beta$-catenin and Bmp signals control distinct sets of transcription factors in cardiac progenitor cells. Proc Natl Acad Sci U S A. 2012;109(27):10921-6.

58. Senyo SE, Lee RT, Kühn B. Cardiac regeneration based on mechanisms of cardiomyocyte proliferation and differentiation. Stem Cell Res. 2014;13(3 Pt B):532-41.

59. Hatzistergos KE, Williams AR, Dykxhoorn D, Bellio MA, Yu W and Hare JM. Tumor Suppressors RB1 and CDKN2a Cooperatively Regulate Cell-Cycle Progression and Differentiation During Cardiomyocyte Development and Repair. Circ Res. 2019;124:1184-1197.

60. Zhou B, von Gise A, Ma Q, Rivera-Feliciano J, Pu WT. Nkx2-5and Isl1-expressing cardiac progenitors contribute to proepicardium. Biochem Biophys Res Commun. 2008;375(3):450-3

61. van Wijk B, van den Berg G, Abu-Issa R, Barnett P, van der Velden S, Schmidt M, Ruijter JM, Kirby ML, Moorman AF, van den Hoff MJ. Epicardium and myocardium separate from a common precursor pool by crosstalk between bone morphogenetic protein- and fibroblast growth factor-signaling pathways. Circ Res. 2009;105(5):431-41.

62. Porrello ER, Mahmoud AI, Simpson E, Johnson BA, Grinsfelder D, Canseco D, Mammen PP, Rothermel BA, Olson EN, Sadek HA. Regulation of neonatal and adult mammalian heart regeneration by the miR-15 family. Proc Natl Acad Sci U S A. 2013;110(1):187-92.

63. Sánchez-Iranzo H, Galardi-Castilla M, Minguillón C, SanzMorejón A, González-Rosa JM, Felker A, Ernst A, GuzmánMartínez G, Mosimann C, Mercader N. Tbx5a lineage tracing shows cardiomyocyte plasticity during zebrafish heart regeneration. Nat Commun. 2018;9(1):428.

64. Hatzistergos KE, Durante MA, Valasaki K, Harbour JW and Hare JM. A novel cardiomyogenic role for Is11+ neural crest cells in the inflow tract. 2019. doi: https://doi.org/10.1101/842864 


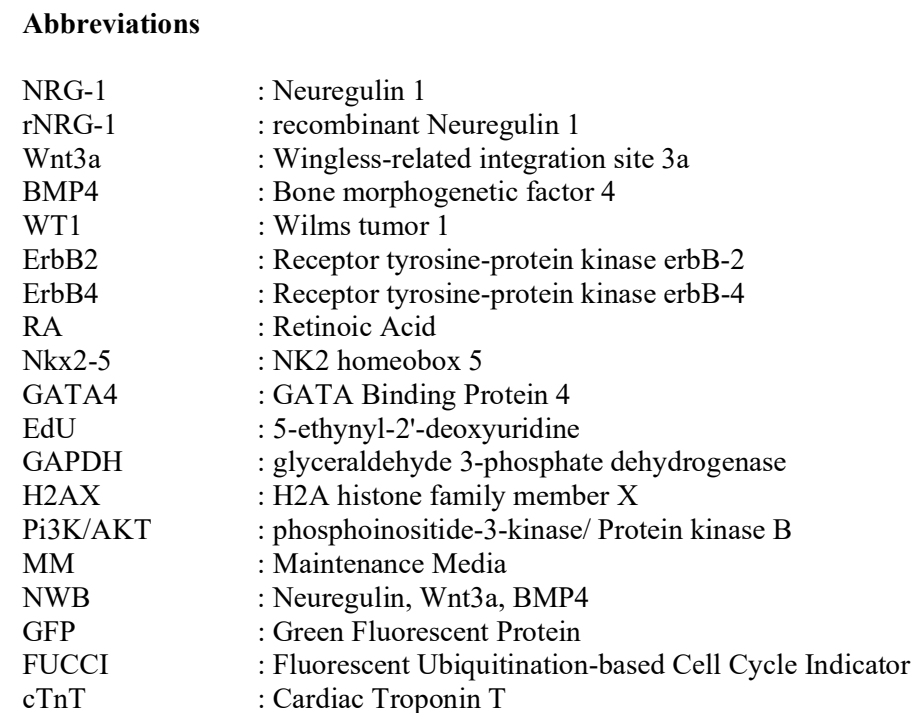

\section{Potential Conflicts of Interests}

1. Author Joshua Hare is Consultant/Shareholder/Board Member of Longeveron; Consultant/Shareholder/Board Member of Vestion; Consultant/Shareholder/Board Member of Heart Genomics and has obtained grants from NHLBI.

2. Author Ian White is Founder and CSO NeoBiosis, LLC.

\section{Additional Information}

Supplementary Information accompanies this article. Supplementary information, Video and figures are linked to the online version of the article.

\section{Corresponding Author}

Ian A. White, Neobiosis, LLC, UF Innovate Institute, 12085 Research Drive, Alachua, FL 32615, USA. Email: ianwhite@ufl.edu 